\title{
Pengaruh Pelayanan Kefarmasian di Rumah pada Pasien Diabetes Melitus Tipe 2 di Puskesmas Wilayah Kota Yogyakarta
}

\author{
The Influence of Home Pharmaceutical Care for Type 2 Diabetes Mellitus Patients at Community Health \\ Centres in Yogyakarta
}

\author{
Nur Rasdianah ${ }^{1}$, Suwaldi Martodiharjo'ㄹ ${ }^{2}$ Tri Murti Andayani², Lukman Hakim² \\ 1. Program Studi Doktor Universitas Gadjah Mada, Universitas Negeri Gorontalo \\ 2. Universitas Gadjah Mada Yogyakarta \\ Submitted: 25-05-2019 Revised: 28-08-2019 Accepted:02-06-2020
}

Korespondensi : Nur Rasdianah : Email : nr.apoteker@gmail.com

\begin{abstract}
ABSTRAK
Prevalensi diabetes melitus (DM) di Indonesia yang semakin meningkat membutuhkan peran serta semua pihak termasuk apoteker. Penelitian ini bertujuan untuk mengetahui dampak uji coba penerapan pedoman pelayanan kefarmasian di rumah bagi pasien diabetes melitus tipe 2 terhadap tingkat pengetahuan, kepatuhan pengobatan, kepuasan terapi dan kontrol glikemik. Penelitian ini menggunakan desain quasi eksperimental dengan one grup pre-test and post-test design yang melibatkan 37 pasien diabetes melitus tipe 2 yang memenuhi syarat inklusi dan eksklusi. Instrument yang digunakan adalah kuesioner pengetahuan Diabetes Knowledge Quesioner (DKQ-24) dan kuesioner kepuasan terapi Diabetes Medication Satisfaction Tool (DMSAT). Kepatuhan pasien diukur dengan metode pillcount dan kadar gula darah puasa (GDP) diperoleh dari data pemeriksaan laboratorium. Penelitian dilakukan pada bulan Maret - Mei 2017 di dua puskesmas dan rumah pasien di wilayah Kota Yogyakarta. Analisis data menggunakan uji Wilcoxon dan uji Spearman. Hasil penelitian menunjukkan bahwa terdapat perubahan tingkat pengetahuan, kepatuhan, kepuasan terapi dan kontrol glikemik sebelum dan sesudah intervensi pelayanan kefarmasian yang dilakukan di rumah pasien. Rerata penurunan kadar gula darah puasa sebelum dan sesudah intervensi sebesar $17.09 \mathrm{mg} / \mathrm{dL} \pm 1,43$.
\end{abstract}

Kata kunci: Pelayanan kefarmasian; Diabetes melitus tipe 2; Pedoman

\section{ABSTRACT}

The increasing prevalence of diabetes mellitus (DM) in Indonesia requires participation of all parties including pharmacists. This study aims to determine the impact of the implementation of home pharmacy service guidelines for patients with type 2 diabetes mellitus on the level of knowledge, medication adherence, therapeurical satisfaction and glycemic control. This study used a quasiexperimental design with one group pre-test and post-test design involving 37 patients with type 2 diabetes mellitus who met the requirements of inclusion and exclusion criterias. The Diabetes Knowledge Questionnaire (DKQ-24) and the Diabetes Medication Satisfaction Tool (DMSAT) were used for collecting the data. Patient adherence was measured using a pillcount method and fasting blood sugar levels (FSB) data were obtained from the laboratory results. The study was conducted in two community health centers and patient's home in the Yogyakarta Municipality area. The data were analysed using Wilcoxon and Spearman test. The results showed the change of the level of knowledge, medication adherence, therapeutic satisfaction and glycemic control before and after intervention of pharmacy services at home. The average decreasing of fasting blood sugar levels $17.09 \mathrm{mg} / \mathrm{dL} \pm 1.43$.

Keywords: Pharmaceutical services; type 2 Diabetes mellitus; Guidelines

\section{PENDAHULUAN}

Diabetes melitus adalah masalah kesehatan masyarakat utama di seluruh dunia, yang membutuhkan perawatan medis dan edukasi manajemen diri pasien yang berkelanjutan untuk mencegah komplikasi akut dan untuk mengurangi risiko komplikasi jangka panjang. Indonesia merupakan salah satu negara di dunia yang memiliki prevalensi diabetes yang tinggi. Berdasarkan Data Diabetes Atlas 2011 yang dirilis oleh International Diabetes Federation (IDF) memperkirakan jumlah penduduk Indonesia berusia 20-79 tahun dengan diabetes di tahun 2030 akan meningkat menjadi 11,8 juta dari 7,3 juta (2011). Peringkat Indonesia juga naik dari 
10 dunia (2011) menjadi 9 (2030) dengan kategori jumlah penduduk berusia di atas 20 tahun yang menderita diabetes. ${ }^{1}$ Menurut Perkeni, berdasarkan pola pertambahan penduduk, diperkirakan pada tahun 2030 penduduk yang berusia di atas 20 tahun akan ada 194 juta dengan asusmsi prevalensi diabetes mellitus pada urban (14,7\%) dan rural $(7,2 \%)$ maka diperkirakan terdapat 12 juta penyandang diabetes di daerah urban dan 8,1 juta di daerah rural. ${ }^{1 B e r d a s a r k a n}$ hasil Riset Kesehatan Dasar (Riskedas) tahun 2013, prevalensi diabetes melitus (DM) di Indonesia meningkat dari $1.1 \%$ (2007) menjadi 2,1\% (2013). Prevalensi penderita DM berdasarkan diagnosis dokter tertinggi terdapat pada Provinsi Daerah Istimewa Yogyakarta, sebesar $2,6 \%{ }^{3}$

Meningkatnya penderita diabetes melitus disebabkan oleh peningkatan obesitas, kurang aktivitas fisik, kurang mengkonsumsi makanan yang berserat, merokok, dan tingginya lemak. Diabetes melitus merupakan penyakit menahun yang umumnya diderita sepanjang sisa hidup penderita, dan perlu pengobatan jangka panjang dengan biaya cukup besar. Beberapa faktor yang berkontribusi terhadap penatalaksanaan penyakit secara optimum meliputi: usia, kompleksitas dari terapi, rejimen terapi yang tidak tepat, durasi penyakit, depresi, kepatuhan dalam mengkomsumsi obat yang diresepkan, dan masalah psikologi. Semuanya memberi efek yang signifikan terhadap kontrol glikemik dan outcome dari terapi diabetes melitus tipe 2. ${ }^{4}$ Selain itu informasi yang tidak lengkap dan tidak adanya penjelasan yang berkesinambungan menjadi kendala pasien untuk menjalankan pengobatan. Pada kenyataannya banyak pasien yang menghentikan pengobatan secara sepihak, mengurangi dosis atau menghilangkan dosis obat. Akibatnya kadar gula darah tidak terkendali sehingga memungkinkan timbulnya komplikasi. Hasil studi pendahuluan yang dilakukan di puskesmas yang berada di wilayah Propinsi DI Yogyakarta terkait pengobatan diabetes melitus tipe 2, dari 239 pasien sebanyak
52,32\% memiliki kepatuhan yang rendah, sebanyak 56,90\% memiliki kadar gula darah yang buruk, 40,59\% kepuasan terapi pada kategori cukup puas. 66,11\% yang tidak melakukan aktifitas fisik dan 76,99\% tidak memiliki pola makan.

Hasil tersebut memerlukan intervensi dari berbagai pihak termasuk apoteker untuk meningkatkan outcome pasien diabetes melitus tipe 2. Penelitian lain menunjukkan peran apoteker dalam bentuk edukasi, konseling, kunjungan residensial dapat meningkatkan kepatuhan pengobatan pasien yang pada akhirnya dapat mempertahankan kadar gula darah pasien tetap terkendali. Pada penelitian sebelumya, telah dikembangkan pedoman kunjungan kefarmasian ke rumah pasien yang merupakan acuan apoteker dalam pelayanan kefarmasian di rumah. Tahapan pelayanan kefarmasian meliputi identifikasi masalah, rencana aksi, monitoring dan evaluasi. Pedoman dilengkapi dengan buku edukasi, leaflet, dan lembar dokumentasi pelayanan kefarmasian. Tujuan penelitian ini untuk mengetahui pengaruh penerapan pedoman pelayanan kefarmasian di rumah bagi pasien diabetes melitus tipe 2 terhadap pengetahuan, kepatuhan pengobatan, kepuasan terapi dan kontrol glikemik.

\section{METODE}

Penelitian ini menggunakan desain penelitian kuasi eksperimen dengan design one grup pre-test and post-test design. Teknik pengambilan sampel dengan metode consecutive sampling. Sampel dihitung menggunakan rumus besar sampel uji hipotesis numerik berpasangan. ${ }^{5}$ Partisipan yang terlibat berjumlah 37 orang yang berasal dari dua puskesmas di kota Yogyakarta. Penelitian dilakukan pada bulan Maret 2017 sampai Mei 2017.

Kriteria inklusi pada penelitian ini adalah laki-laki dan perempuan, berusia $>18$ tahun, didiagnosa dokter menderita diabetes melitus tipe 2, mendapat terapi antidiabetes oral dengan atau tanpa insulin, menyetujui untuk mengikuti penelitian dengan 
menandatangani lembar persetujuan. Kriteria eksklusi adalah pasien dengan kadar gula darah puasa tidah terkendali, mengalami gangguan fungsi pendengaran, tidak mampu diajak berkomunikasi dan tidak mampu berbahasa Indonesia.

Pelayanan kefarmasian dilakukan di puskesmas dan di rumah pasien di wilayah Daerah Istimewa Yogyakarta selama 2 bulan dengan kunjungan sebanyak 3 kali dengan durasi 45 menit dan jarak antar kunjungan yaitu 1 bulan. Pemilihan pasien dilakukan di ruang pelayanan farmasi. Partisipan yang dipilih merupakan pasien yang memiliki kadar gula darah puasa tidak terkendali minimal 3 bulan terakhir (berdasarkan data rekam medis). Partisipan yang bersedia mengikuti penelitian mengisi informed consent. Pengisian kuesioner dilakukan langsung oleh partisipan. Apabila partisipan tidak bersedia mengisi sendiri maka kuesioner dibacakan oleh peneliti dan partisipan mengisi sendiri sesuai jawaban yang dipilih pada lembar kuesioner. Apabila partisipan juga tidak bersedia mengisi sendiri jawaban pada lembar kuesioner maka peneliti mengisi lembar jawaban kuesioner sesuai respon yang diberikan oleh partisipan pada saat itu juga. Kuesioner yang digunakan terdiri dari Kuesioner tingkat pengetahuan menggunakan Diabetes Knowledge Quesioner (DKQ-24) dan kuesioner kepuasan terapi Diabetes Medication Satisfaction Tool (DMSAT). Kuesioner yang digunakan menggunakan versi bahasa Indonesia.Hasil uji validitas dan realibilitas instrumen penelitian DMSAT diperoleh $\mathrm{r}$ hitung $>0,300$ dan 0,361 dan cronbach alpha $=$ $(0,967$ dan 0,905$)>$ rtabel. 6,7 dan instrumen DKQ24 diperoleh $\mathrm{r}$ hitung $>0,344$ dan cronbach alpha $=0,856>0,6$. Pengukuran kepatuhan minum obat menggunakan metode pill count serta data kadar gula darah puasa menggunakan data hasil pemeriksaan laboratorium pasien. Pengukuran dilakukan pada setiap kunjungan.

Pelayanan kefarmasian dilakukan oleh peneliti bekerjasama dengan apoteker puskesmas menggunakan Pedoman Pelayanan Kefarmasian di Rumah. Apoteker puskesmas membantu memilih pasien yang memenuhi kriteria sedangkan kunjungan ke rumah dilakukan secara langsung oleh peneliti. Tahapan pelaksanaan saat kunjungan ke rumah partisipan yaitu a) Kunjungan pertama: Pada sesi awal ( $\pm 5-15$ menit pertama) perkenalan dan diskusi ringan untuk membangun hubungan saling percaya dengan partisipan dan keluarganya, membahas manfaat dari pelayanan kunjungan kefarmasian yang dilakukan. Pada sesi kedua ( $\pm 5-15$ menit), penggunaan obat, kepatuhan, hambatan atau kendala yang dihadapi partisipan di identifikasi dan evaluasi. Pada sesi ini juga disusun rencana tindak lanjut. Pada sesi ketiga ( $\pm 5-10$ menit $)$ dilakukan edukasi sesuai kebutuhan individu. Partisipan juga di motivasi untuk mengikuti rencana yang sudah disusun. Sebelum pamit dilakukan penyusunan jadwal untuk pertemuan berikutnya. b) Kunjungan kedua dilakukan setelah satu bulan dari kunjungan pertama. Pada saat kunjungan kedua, rencana yang telah disusun pada pertemuan pertama di evaluasi termasuk masalah baru yang kemungkinan timbul dalam selang waktu sebelumnya. Penilain hambatan kepatuhan yang dialami partisipan dan cara mengatasinya. Edukasi kembali dilakukan sesuai kebutuhan partisipan. Rencana tindak lanjut berikutnya disusun kembali termasuk menetapkan target yang ingin dicapai partisipan. c) Kunjungan ketiga dilakukan setelah satu bulan dari kunjungan kedua: siklus sama dengan pertemuan kedua. Perbedaan pada tidak ada sesi monitoring untuk tindak lanjut berikutnya..

Pedoman Pelayanan Kefarmasian di Rumah merupakan panduan pelayanan kunjungan kefarmasian yang berisi tahapan pelayanan kunjungan kefarmasian, dilengkapi dengan buku edukasi dan brosur. Buku pedoman berisi latar belakang, tujuan, prosedur, instrumen, materi, bacaan yang dianjurkan. Latar belakang berisi informasi yang mendasari pentingnya dilakukan pelayanan kunjungan kefarmasian (home pharmaceutical care service) pada pasien diabetes mellitus tipe 2 . Tujuan berisi target 
Tabel I. Karakteristik pasien diabetes meltus tipe $2(\mathrm{~N}=37)$

\begin{tabular}{|c|c|c|c|}
\hline Variabel & & Variabel & \\
\hline Jenis kelamin & & Status Sosial & \\
\hline Laki-laki & $8(21,62)$ & Menikah & $36(97,30)$ \\
\hline Perempuan & $29(78,38)$ & Tidak & $1 \quad(2,70)$ \\
\hline Usia & & Kehidupan sosial & \\
\hline$<60$ tahun & $24(64,86)$ & Tinggal sendiri & $3(8,11)$ \\
\hline$\geq 60$ tahun & $13(35,14)$ & Tinggal dengan keluarga & $34(91,89)$ \\
\hline Pekerjaan & & Anti Diabetes Oral (ADO) & \\
\hline Bekerja & $18(48,65)$ & Tunggal & $5 \quad(13,51)$ \\
\hline Tidak bekerja & $19(51,35)$ & Kombinasi & $32(86,49)$ \\
\hline Pendidikan & & Item Obat & \\
\hline Tidak Tamat & $4 \quad(10,81)$ & 2 & $4 \quad(10,81)$ \\
\hline SD & $14(37,84)$ & 3 & $13(35,14)$ \\
\hline SMP & $12(32,43)$ & 4 & $17(45,94)$ \\
\hline SMA & $16(43,24)$ & 5 & $3(8,11)$ \\
\hline Durasi DM & & DM & \\
\hline$<5$ tahun & $21(56,76)$ & Tanpa komorbid & $11(29,73)$ \\
\hline$\geq 5$ tahun & $16(43,24)$ & Dengan komorbid & $26(70,27$ \\
\hline
\end{tabular}

yang diharapkan setelah pelayanan kefarmasian, waktu dan tempat berisi informasi tempat pelayanan kefarmasian dilakukan, instrumen berisi perlengkapan yang disiapkan saat pelayanan kefarmasian berupa buku edukasi, brosur dan form dokumentasi. Buku edukasi dan brosur berisi materi pengetahuan tentang diabetes melitus, komplikasi diabetes, penggunaan obat diabetes, diabetes pada kondisi khusus.

Data yang diperoleh dianalisis menggunakan uji Wilcoxon dan uji Spearman menggunakan program SPSS 16. Data yang dianalis secara statistik adalah data sebelum intervensi (kunjungan ke-1) dan sesudah intervensi (kunjungan ke-3). Penelitian ini telah mendapatkan persetujuan etik dengan nomor Ref: KE/FK/962/EC/2016 dari Komisi Etik Fakultas Kedokteran Universitas Gadjah Mada Yogyakarta.

\section{HASIL DAN PEMBAHASAN Karakteristik Pasien}

Penelitian dilakukan pada pasien diabetes melitus tipe 2 di Yogyakarta dengan total jumlah partisipan menyelesaikan penelitian sebanyak 37 pasien dari 41 total jumlah partisipan yang direkrut, sisanya sebanyak 4 partisipan tidak berhasil menyelesaikan penelitian. Kunjungan ke rumah partisipan dilakukan di awal, pertengahan, dan akhir penelitian. Kunjungan berlangsung selama 2 bulan untuk setiap pasien. Dari 37 partisipan sebanyak 78,38\% merupakan pasien perempuan, 43,24\% berpendidikan menengah atas, 51,35\% tidak bekerja, menikah dan hidup dengan keluarga, $56,76 \%$ menderita diabetes melitus kurang dari 5 tahun, 70,27\% mendapat obat oral diabetes kombinasi yaitu metformin dan glimepiride. Kadar glukosa darah puasa ratarata 153,11 $\pm 29,32 \mathrm{mg} / \mathrm{dl}$. Karakteristik pasien dapat dilihat pada tabel I.

Berdasarkan kategori jenis kelamin, jumlah penderita diabetes tipe 2 terbanyak dialami oleh jenis kelamin perempuan sebanyak 78,38\%. Menurut hasil riset kesehatan dasar tahun 2013 prevalensi diabetes melitus pada perempuan cenderung lebih tinggi dari pada laki-laki. Ini seiring dengan juga meningkatnya proporsi obesitas atau kegemukan yang juga terus meningkat, dari 18,8\% tahun 2007 menjadi 26.6\% di 2013. Obesitas dianggap sebagai faktor risiko yang 
berkaitan erat dengan beberapa penyakit kronis termasuk diabetes. Peningkatan obesitas pada perempuan dewasa $(>18$ tahun) cenderung lebih tinggi dibanding laki-laki. Obesitas pada perempuan meningkat dari 14,8 \% (2007) menjadi 32,9\% (2013), sedangkan laki-laki hanya 13,9\% menjadi $19,7 \%{ }^{3}$

Berdasarkan usia partisipan, kelompok usia yang menderita diabetes melitus dibawah 60 tahun sebanyak 64,86\%. Menurut hasil riset kesehatan (2013) prevalensi diabetes melitus berdasarkan diagnosis dokter dan gejala meningkat sesuai dengan bertambahnya umur, namun mulai umur $\geq 65$ tahun cenderung menurun. ${ }^{3}$ Umur harapan hidup di propinsi Daerah Istimewa Yogyakarta mencapai 74 tahun, lebih tinggi dibandingkan dengan umur harapan hidup nasional yaitu 69,43 tahun. ${ }^{8}$

Distribusi durasi penyakit diabetes, sebanyak 56,76\% partisipan menderita diabetes melitus kurang dari 5 tahun. Pasien dengan komorbid sebanyak 70,27\%. Hipertensi merupakan jenis komorbid yang paling banyak menyertai penderita diabetes kemudian dislipidemia atau diabetes dengan dua komorbid yaitu diabetes dengan hipertensi dan dislipidemia, selain itu komorbid lainnya yaitu obesitas. Dislipidemia pada penderita diabetes melitus lebih meningkatkan risiko timbulnya penyakit kardiovaskular. Prevalensi obesitas pada diabetes melitus cukup tinggi, demikian pula sebaliknya kejadian diabetes melitus dan gangguan toleransi glukosa pada obesitas sering dijumpai. ${ }^{9}$

\section{Pengaruh Kefarmasian Pengetahuan}

\section{Pelayanan terhadap}

Kunjungan Penilaian

tingkat pengetahuan

dilakukan setiap kunjungan. Kunjungan dilakukan sebanyak 3 kali dengan jarak antar kunjungan 1 bulan. Berdasarkan hasil penilaian pengetahuan partisipan tentang diabetes pada saat kunjungan pertama kali dilakukan, diketahui bahwa terdapat lima partisipan yang mengakui sudah sering mendapatkan informasi tentang penyakit diabetes, namun masih sulit untuk menerapkan sepenuhnya apa yang mereka ketahui. Sebagian lainnya tidak mampu mengenali timbulnya gejala hipoglikemia sehingga tidak mengetahui cara mengatasinya. Sebanyak 3 partisipan sangat antusias mengikuti edukasi yang diberikan, mereka menganggap kunjungan yang dilakukan membuat mereka dihargai dan diperhatikan. Satu partisipan melaporkan bahwa dirinya tidak memahami apa yang disampaikan oleh petugas dipuskesmas, namun tidak berani untuk bertanya. Partisipan kesulitan untuk mengatur pola makan, selain diabetes partisipan menderita hipertensi dan dislipidemia. Bentuk intervensi yang dapat dilakukan untuk mengatasi masalah pada tahapan ini adalah edukasi. Dari hasil penilaian awal terhadap pengetahuan tentang diabetes pada setiap pasien, dapat diidentifikasi bagian pengetahuan yang masih kurang, kemudian dilakukan edukasi dengan bantuan buku edukasi dan leaflet terkait diabetes dan pengobatannya. Buku edukasi berisi Pengetahuan tentang diabetes, Faktor resiko, Hipoglikemik dan hiperglikemik serta cara mengatasinya, Komplikasi diabetes, Penggunaan obat, dosis, cara penggunaan, serta Diabetes pada kondisi khusus. Pemberian edukasi dilakukan selama 10-15 menit di rumah pasien dengan materi edukasi terutama difokuskan pada hal-hal yang belum diketahui pasien. Edukasi dilakukan juga terhadap keluarga partisipan apabila pada saat kunjungan dilakukan, keluarga partisipan bersedia untuk mendampingi. Kemampuan partisipan menerima edukasi umumnya lambat, hal ini mungkin disebabkan karena faktor usia dan tingkat pendidikan yang rendah. Untuk itu penyampaian dilakukan dengan bahasa yang mudah diterima oleh pasien. Pada kunjungan kedua, dilakukan penilaian kembali terhadap pengetahuan partisipan untuk mengetahui perkembangan tingkat pemahaman partisipan terhadap edukasi yang sudah dilakukan pada pertemuan pertama. Kemudian edukasi dilakukan lagi dengan berfokus pada hal-hal 
Tabel II. Tingkat pengetahuan pasien, kepatuhan (pill count), kepuasan terapi pasien diabetes melitus tipe 2 sebelum dan sesudah pelayanan kunjungan kefarmasian

\begin{tabular}{lccc}
\hline & $\begin{array}{c}\text { Sebelum } \mathbf{n}=\mathbf{3 7} \\
\text { Median }(\mathbf{m i n}-\mathbf{m a x})\end{array}$ & $\begin{array}{c}\text { Sesudah } \mathbf{n}=\mathbf{3 7} \\
\text { Median }(\mathbf{m i n}-\mathbf{m a x})\end{array}$ & Nilai $\mathbf{p}^{*}$ \\
\hline Pengetahuan & $13(8-18)$ & $18(12-21)$ & 0,000 \\
Kepatuhan (pill count) & $92(83-100)$ & $98(93-100)$ & 0,000 \\
Kepuasan terapi & $7,10(6-8)$ & $7,90(7-10)$ & 0,000 \\
\hline
\end{tabular}

*uji Wilcoxon Signed Rank (data tidak berdistribusi normal).

yang belum diketahui partisipan. Pada pertemuan ketiga hal yang sama dilakukan kembali. Secara keseluruhan edukasi dilakukan tiga kali selama pelayanan kunjungan kefarmasian. Hasil penelitian yang dianalis secara statistik adalah hasil pengukuran kunjungan awal sebelum intervensi dan hasil pengukuran akhir setelah intervensi. Berdasarkan hasil penelitian, rerata skor pengetahuan (median; min-max) sebesar 13 (8-18) sebelum intervensidan meningkat menjadi 18 (8-24) setelah dilakukan pelayanan kefarmasian di rumah (tabel II). Dari hasil analisis uji Wilcoxon, diperoleh nilai $p=0,000$ $<0,05$ yang berarti intervensi yang dilakukan di rumah pasien menunjukkan perubahan tingkat pengetahuan terkait diabetes dan kepatuhan pengobatan pada pasien dengan diabetes melitus tipe 2. Stroup dkk, (2003) dalam suatu penelitian melaporkan bahwa kunjungan rumah dalam waktu panjang dan bulanan berpotensi meningkatkan pemahaman pasien dan kepatuhan pasien terhadap gaya hidup, terapi farmakologis dan pemantauan penyakit yang memberi dalam memperbaiki status kesehatan. ${ }^{10}$ Metode pendidikan dan konseling pasien berbasis rumah memberi hasil yang memuaskan. ${ }^{11}$ Pemberian edukasi disertai booklet dapat meningkatkan pengetahuan pasien diabetes melitus. ${ }^{12}$ Kunjungan rumah yang berfokus pada pendidikan pasien dan intervensi perilaku membantu meningkatkan kontrol glikemik pada pasien diabetes. ${ }^{13}$

Berdasarkan hasil pengolahan data skor pengetahuan diketahui nilai rerata skor pengetahuan 13 (8-18) sebelum intervensi dan nilai rerata sesudah intervensi sebesar
18 (12-21). Dari hasil analisis statistik menggunakan uji Wilxcoxon diketahui terdapat perbedaan antara sebelum dan sesudah intervensi (tabel II).

Hasil penelitian menunjukkan adanya perubahan tingkat pengetahuan sebelum dan sesudah penerapan pedoman pelayanan kunjungan kefarmasian. Salah satu upaya yang dapat dilakukan apabila pasien yang mendapatkan informasi yang tidak benar mengenai penyakit diabetes seperti penggunaan obat yang terus menerus dapat memperparah penyakit, dapat diluruskan dengan pemberian edukasi. Pendidikan terstruktur memiliki dampak positif pada kontrol glukosa dan hipoglikemia pada diabetes tipe 2 dan merupakan program wajib dalam perawatan rutin. ${ }^{14}$ Program edukasi yang menekankan kepatuhan terhadap rejimen pengobatan secara keseluruhan, terutama untuk diet dan berolahraga serta tindak lanjut yang teratur memiliki manfaat lebih besar dalam kontrol glikemik dibandingkan dengan hanya menekankan pada kepatuhan pengobatan saja. ${ }^{15}$

\section{Pengaruh Pelayanan Kunjungan Kefarmasian terhadap Kepatuhan Pengobatan}

Pada kunjungan awal ke rumah pasien, secara umum masalah penggunaan obat yang diperoleh adalah ketidakpatuhan pasien. Berdasarkan hasil penilaian (asesmen) yang dilakukan pada setiap pasien menggunakan panduan pelayanan diketahui masalahmasalah ketidakpatuhan pada pasien disebabkan oleh faktor lupa, bosan, rasa tidak nyaman akibat timbulnya efek samping dan ketakutan dengan penggunaan obat jangka 
panjang yang akan berakibat pada penyakit ginjal. Berdasarkan penggalian informasi diketahui terdapat pasien yang mengambil tindakan sendiri dengan mengurangi dosis bahkan menghentikan pengobatan tanpa berkonsultasi ke dokter puskesmas tempat pasien rutin kontrol setiap bulannya. Tindakan atau bentuk intervensi yang dilakukan pada pasien jenis ini yaitu pemberian edukasi dan konseling agar pasien memahami bahwa penggunaan obat atau peresepan obat yang dilakukan oleh dokter sudah melalui pertimbangan tertentu sesuai kondisi pasien. Bagi pasien yang mengalami kendala kepatuhan karena faktor lupa maka bentuk intervensi yang bisa diberikan pada pasien yaitu dengan meminta pasien meletakkan obat ditempat yang paling strategis dan mudah dijangkau seperti di dekat meja makan, di dekat televisi atau di tempat pasien sering beraktifitas dengan tetap memperhatikan cara penyimpanan obat yang benar. Selain itu memberi edukasi kepada keluarga pasien agar mendukung pasien untuk meminum obat secara teratur. Bagi pasien yang tidak patuh karena bosan diberi motivasi agar tetap dapat menjalani terapi sesuai aturan. Dari 37 partisipan, terdapat 30 partisipan yang memiliki tingkat kepatuhan yang meningkat setelah intervensi, dan terdapat 2 partisipan yang tidak mampu mempertahankan kepatuhan (tabel III). Partisipan yang mengalami penurunan kepatuhan di identifikasi mengalami masalah keluarga sehingga membuat mereka stress, yang pada akhirnya berpengaruh pada kepatuhan minum obat. Partisipan difasilitasi untuk mendapatkan bantuan dibagian psikologi Puskesmas.

Pengukuran tingkat kepatuhan dengan metode pill count yaitu menghitung sisa obat yang masih dimiliki pasien dibandingkan dengan jumlah obat yang diterima oleh pasien untuk satu bulan. Perhitungan jumlah obat dilakukan pada saat kunjungan ke-1 dilakukan dengan menghitung sisa obat yang dimiliki pasien sebelumnya. Selanjutnya perhitungan sisa obat antara kunjungan ke-1 dengan ke-2, dan antara kunjugan ke-2 dengan ke-3. Hasil pill count menunjukkan bahwa rerata tingkat kepatuhan sebesar 92 (83-100) sebelum intervensi dan meningkat menjadi 98 (93-100) setelah dilakukan kunjungan pelayanan kefarmasian (tabel II). Hasil penelitian ini sejalan dengan penelitian sebelumnya, bahwa kepatuhan pasien meningkat setelah mendapatkan intervensi dari apoteker. 11,16,17 Intervensi berupa kunjungan rumah mampu meningkatkan kepatuhan penggunaan obat sehingga dapat menunjang keberhasilan terapi pasien ${ }^{18,19}$

\section{Pengaruh Pelayanan Kefarmasian terhadap Tingkat Kepuasan Terapi}

Kepuasan terapi merupakan capaian dari usaha yang dilakukan pasien selama menjalani pengobatan. Kontrol gula darah yang terkendali secara tidak langsung akan meningkatkan kepuasan. Salah satu jenis outcome humanis yang digunakan sebagai pelengkap pengukuran outcome selain kadar GDP dan $\mathrm{HbA1c}$ adalah kepuasan terapi.

Pada awal kunjungan sebelum intervensi dilakukan, rerata (median: minmax) skor kepuasan terapi pasien adalah 7,10 (6-8) dan meningkat menjadi 7,90 (7-10) setelah intervensi (tabel II). Hal ini menunjukkan bahwa terdapat perubahan tingkat kepuasan terapi setelah dilakukan pelayanan kefarmasian di rumah pasien. Kemungkinan meningkatnya tingkat kepuasan terapi partisipan karena bentuk intervensi yang bersifat individu sehingga memungkinkan partisipan lebih leluasa atau terbuka untuk mengutarakan permasalahan yang mereka alami. Permasalahan atau hambatan yang dialami karena keterbatasan waktu dan lamanya antrian dipusat pelayanan kesehatan menyebabkan interaksi pasien dengan apoteker atau tenaga kesehatan lainnya sangat terbatas, sehingga partisipan mengalami kendala untuk mendiskusikan persoalan pengobatan yang dialami. Pelayanan kefarmasian di rumah membuka ruang bagi pasien dan keluarganya untuk berdiskusi secara terbuka dengan apoteker 
Tabel III. Pengaruh kunjungan kefarmasian terhadap luaran klinik (kadar gula darah puasa)

\begin{tabular}{ccc}
\hline $\begin{array}{c}\text { Sebelum } \mathbf{n}=33 \\
\text { Median (min-max) }\end{array}$ & $\begin{array}{c}\text { Sesudah } \mathbf{n}=33 \\
\text { Median (min-max) }\end{array}$ & Nilai $\mathbf{p}$ \\
\hline $\mathbf{1 3 7} \mathbf{~ m g / d L ~ ( 1 1 9 - 2 3 7 ) ~}$ & $125 \mathrm{mg} / \mathrm{dL}(101-211)$ & $0,000^{*}$ \\
\hline
\end{tabular}

Keterangan: uji Wilcoxon Signed Rank (data tidak berdistribusi normal)

untuk mencari solusi terbaik. Kepuasan terapi dapat memaksimalkan pengobatan sehingga bermanfaat bagi pasien. $6,7,20$.

\section{Pengaruh Pelayanan Kefarmasian terhadap Kontrol Glikemik \\ Dari 37 partisipan, pada akhir} intervensi sebanyak 33 pasien yang melakukan pemeriksaan kadar gula darah puasa dan terdapat 4 partisipan tidak berpuasa pada saat jadwal pengukuran kadar gula darah puasa sehingga tidak diperoleh hasil pemeriksaan kadar gula darahnya. Berdasarkan hasil pengukuran kadar gula darah puasa pada 33 partisipan, rerata kadar gula darah puasa sebelum intervensi adalah 137 mg/dL (119-237 mg/dL) dan mengalami penurunan kadar gula darah puasa setelah partisipan mendapatkan intervensi sebesar $125 \mathrm{mg} / \mathrm{dL}$ (101-211 mg/dL).

Berdasarkan analisis uji statistik mengunakan uji wilcoxon signed rank menunjukkan nilai $\mathrm{p}=0,000(\mathrm{p}<0,05)$ yang berarti bahwa terdapat perubahan yang signifikan antara kadar gula darah puasa sebelum dan sesudah intervensi. Dalam satu penelitian jangka pendek yang dilakukan oleh Hillen (2011) berupa program pemantauan intensif, pemberian edukasi, dan intervensi farmakologis menghasilkan peningkatan kontrol glikemik yang dramatis dalam waktu 1,5 bulan, dan efek ini berkelanjutan hingga 3 bulan. Edukasi yang diberikan secara individu pada pasien diabetes menghasilkan hasil kontrol glukosa yang lebih baik. ${ }^{21}$ Rerata penurunan kadar gula darah puasa sebelum dan sesudah intervensi sebesar $17.09 \mathrm{mg} / \mathrm{dL} \pm$ 1,43 .

Pemberian pelayanan kefarmasian di rumah pada penelitian ini diharapkan dapat memperbaiki kadar gula darah agar tetap terkendali, sehingga memperlambat proses memburuknya penyakit atau mencegah timbulnya komplikasi. Berdasarkan American Diabetes Association (2015), target terapi yang diinginkan untuk kadar gula darah puasa adalah 80-130 mg/dL dan kadar gula darah 2 jam setelah makan adalah $<180 \mathrm{mg} / \mathrm{dL} .^{20}$ Pemberian pelayanan kunjungan dapat meningkatkan kepatuhan dan juga berpengaruh terhadap hasil luaran klinik yaitu berupa peningkatan ketercapaian target terapi kadar gula darah puasa yang signifikan dengan nilai $\mathrm{p}<0,05$ (Tabel III). Berdasarkan penelitian sebelumnya menunjukkan bahwa pelayanan kefarmasian berupa pelayanan residensial kefarmasian mampu meningkatkan kepatuhan penggunaan obat pasien sehingga dapat menunjang keberhasilan terapi pasien, ${ }^{18}$ kunjungan rumah dapat memperbaiki kontrol glikemik dan mengurangi faktor risiko kardivaskuler, sehingga efektif dalam manajemen diabetes dan meningkatkan kualitas hidup pasien selain itu pada pemberian pelayanan kefarmasian berupa konseling dengan alat bantu (booklet dan penggunaan wadah khusus) lebih efektif menurunkan kadar gula darah dibanding konseling biasa. ${ }^{23,24,25}$

\section{Hubungan kepatuhan pengobatan dengan kontrol glikemik}

Berbagai penelitian menunjukkan bahwa kepatuhan berhubugan erat dengan kadar gula darah yang terkendali. Hubungan tingkat kepatuhan dengan luaran klinik berupa kadar gula darah puasa dianalisis menggunakan uji korelasi Spearman. Tingkat kekuatan korelasi antara kepatuhan dengan kadar gula darah puasa adalah sebesar $-0,515$ 
dengan nilai signifikansi 0,01 yang bermakna bahwa terdapat korelasi yang kuat antara tingkat kepatuhan dengan penurunan kadar gula darah puasa. Koefisien korelasi yang dihasilkan bernilai negatif atau tidak searah yang berarti semakin tinggi tingkat kepatuhan maka kadar gula darah makin menurun. Nilai sig. $($ sig-2 tailed $)=0,002<0,05$ maka terdapat hubungan antara kepatuhan dan kadar gula darah puasa. Hal ini sesuai dengan penelitian sebelumnya yang menyatakan bahwa tercapainya luaran klinik dipengaruhi oleh tingkat kepatuhan yang tinggi. ${ }^{26}$

Pengetahuan diabetes dan kepatuhan pengobatan yang lebih tinggi dan penggunaan terapi tunggal merupakan prediktor signifikan dari kontrol glikemik yang baik dalam analisis multivariate, ${ }^{27}$ tanpa pengetahuan yang cukup, pasien tidak dapat mengelola perawatan diri sendiri secara efisien. Akibatnya, pasien gagal mematuhi instruksi perawatan yang berakibat negatif seperti perkembangan penyakit, menurunkan kualitas hidup, peningkatan biaya perawatan kesehatan dan menimbulkan kematian. Penelitian lain yang menunjukkan hasil bahwa terdapat korelasi positif yang signifikan tetapi lemah antara pengetahuan terkait diabetes dan kepatuhan pengobatan. ${ }^{28}$

Penelitian ini memiliki beberapa keterbatasan terkait dengan jumlah sampel yang sedikit, sumber sampel yang terbatas, tidak ada kelompok kontrol, dan durasi intervensi yang dilakukan hanya dua bulan, sehingga tidak diketahui perubahan perilaku pasien dalam mempertahankan kepatuhan dan luaran kliniknya, Selain itu luaran klinik yang diukur hanya kadar gula darah puasa.

\section{KESIMPULAN}

Pelayanan kefarmasian yang dilakukan sebelum dan sesudah kunjungan ke rumah pasien menunjukkan perubahan tingkat pengetahuan, kepatuhan minum obat, kepuasan terapi dan tercapainya kadar gula darah puasa pada kondisi terkendali. Kepatuhan pengobatan dan kepuasan terapi mungkin merupakan faktor yang memberi pengaruh pada perbaikan kadar gula darah.

\section{KONFLIK KEPENTINGAN}

Pemilihan pasien yang melibatkan apoteker puskesmas mungkin dapat mempengaruhi partisipan yang merupakan pasien rutin pada puskesmas tersebut.

\section{DAFTAR PUSTAKA}

1. Whiting, D.R., Guariguata, L., Weil, C., dan Shaw, J. IDF diabetes atlas: Global estimates of the prevalence of diabetes for 2011 and 2030. Diabetes Research and Clinical Practice, 2011; 94: 311-321

2. Rudianto, A., Dharma, L., Eva, D., Alwi, S., Tri, J.E.T., IGN, A., dkk. Konsensus Dm Tipe 2 Indonesia 2011. URL: (diakses tanggal 2/4/2015)

3. Kementerian Kesehatan Republik Indonesia. Riset Kesehatan Dasar (RISKESDAS) 2013. Badan Penelitian dan Pengembangan Kesehatan.http://labdata.litbang.depke s.go.id/risetbadanlitbangkes/menuriske snas/menu-riskesdas/374rkd2013.

Dipublikasikan 2013. Diakses 19 Mei 2015

4. Cramer, J.A. A systematic review of adherence with medications for diabetes. Diabetes Care. 2004; 27: 12181224.

5. Dahlan, S.M.Besar sampel dan cara pengambilan sampel dalam penelitian kedokteran dan kesehatan. Edisi 3. Salemba Medika, Jakarta. 2013; 20-22

6. Chalik, R. Kepatuhan dan kepuasan terapi dengan antidiabetik oral pada pasien diabetes melitus tipe 2 rawat jalan di RSUP Dr. Sardjito Yogyakarta', , Thesis, . Universitas Gadjah Mada, Yogayakarta.2012;68-69.

7. Nugraheni, A.Y. Pengaruh Pemberian Konseling Farmasis dengan Alat Bantu Terhadap Kepatuhan dan Outcome Klinik Pasien Diabetes Melitus Tipe 2 Anggota Prolanis pada Doketer Keluarga, Thesis, Universitas Gadjah Mada, Yogyakarta. 2015;41-42

8. Dinas Kesehatan DIY. Profil Kesehatan Daerah Istimewa Yogyakarta Tahun 2016 (data tahun 2015) 
9. Rudijanto, A., Yuwono, A., Manaf, A., Pramono, B., Lindarto, D., Purnamasari, D., dkk. Konsensus Pengelolaan dan Pencegahan Diabetes Melitus tipe 2 di Indonesia tahun 2015.

10. Stroup, J., Kane, M.P., Busch, R.S., Bakst, G., dan Hamilton, R.A. The Diabetes Home Visitation Program. American Journal of Pharmaceutical Education. 2003; 67: 91.

11. Chow, E.P., Hassali, M.A., Saleem, F., dan Aljadhey, H. Effects of pharmacistled patient education on diabetesrelated knowledge and medication adherence: A home-based study. Health Education Journal. 2016; 75: 421-433.

12. Radoti M., Arozal, W., Sauriasari, R., dan Keban, S. Evaluasi penerapan booklet dan edukasi apoteker pada pasien diabetes melitus tipe 2 di rumah sakit Mayapada Tangerang. Pharmaceutical Sciences and Research. 2017; 4: 102-110.

13. Han, L., Ma, Y., Wei, S., Tian, J., Yang, X., Shen, X., dkk. Are home visits an effective method for diabetes management? A quantitative systematic review and meta-analysis. Journal of Diabetes Investigation. 2017; 8: 701-708.

14. Yorke, E. dan Atiase, Y. Impact of structured education on glucose control and hypoglycaemia in Type-2 diabetes: a systematic review of randomized controlled trials. Ghana Medical Journal. 2018; 52:41.

15. Al-Rasheedi, A.A.S. The role of educational level in glycemic control among patients with type II diabetes mellitus. International Journal of Health Sciences. 2014;8: 177-187.

16. Manju, C.S., Razak, R., Chandni, R., dan Athira, B. Pharmacist intervention in medication adherence in patients with type II diabetes mellitus. International Journal of Pharmaceutical Sciences and Research. 2016; 7(1): 358-362.

17. Saleem, F., Hassali, M.A., Shafie, A.A., Ul Haq, N., Farooqui, M., Aljadhay, H., dkk. Pharmacist intervention in improving hypertension-related knowledge, treatment medication adherence and health-related quality of life: a non-clinical randomized controlled trial. Health Expectations. 2015;18: 1270-1281.

18. Ichwari, N.P.., Wirasuta, I.M.A.., dan Susanti, N. Akseptabilitas pelayanan residensial kefarmasian pada pasien diabetes melitus tipe 2 tanpa komplikasi. Jurnal Farmasi Udayana. 2013;1-5.

19. Gillani, S.W., Azhar Syed Sulaiman, S., Baig, M., Oktavia Sari, Y., Maisharah Sheikh Ghadzi, S., Noor Haroon, S., dkk. Pharmacist intervention in home care program for diabetes patients. Journal of Diabetes Mellitus. 2012;02: 279293.

20. Hendrychova, T., Vytrisalova, M., Smahelova, Vlcek, J., dan Kubena. Adherence in adults with type 1 diabetes mellitus correlates with treatment satisfaction but not with adverse events. Patient Preference and Adherence. 2013; 867-876.

21. Sperl-Hillen, J. Comparative effectiveness of patient education methods for type 2 diabetes: A Randomized Controlled Trial. Archives of Internal Medicine. 2011;171: 2001-2010.

22. American Diabetes Association. Standards of Medical Care in Diabetes 2015. Diabetes Care. 2015;38: S1-S2.

23. Suppapitiporn, S., Chindavijak, B., dan Onsanit, S. Effect of diabetes drug counseling by pharmacist, diabetic disease booklet and special medication containers on glycemic control of type 2 diabetes mellitus: a randomized controlled trial. Journal of the Medical Association of Thailand, Chotmaihet Thangphaet. 2005;88 Suppl 4: S134-141.

24. Nugraheni, A.Y. dan Sari, I.P. Pengaruh konseling apoteker dengan alat bantu pada pasien diabetes melitus Tipe 2 . Jurnal Manajemen dan Pelayanan Farmasi. 
2015;5:225-235.

25. Presetiawati, I., Andrajati, R., dan Sauriasari, R. Effectiveness of a medication booklet and counseling on treatment adherence in type 2 diabetes mellitus in patients. International Journal of Applied Pharmaceutics. 2017;9: 28-31

26. Morello, C.M., Chynoweth, M., Kim, H., Singh, R.F., dan Hirsch, J.D. Strategies to improve medication adherence reported by diabetes patients and caregivers: results of a taking control of your diabetes survey. The Annals of Pharmacotherapy. 2011;45;145-153.
27. Al-Qazaz, H.K., Sulaiman, S.A., Hassali, M.A., Shafie, A.A., Sundram, S., AlNuri, R., dkk. Diabetes knowledge, medication adherence and glycemic control among patients with type 2 diabetes. International Journal of Clinical Pharmacy. 2011;33: 1028-1035.

28. Nazir, S., Hassali, M., Saleem, F., Bashir, S., dan Aljadhey, H. Association Between Diabetes-related Knowledge and Medication Adherence: Results From Cross-sectional Analysis. Altern Ther Health Med. 2016;22: 8-13. 